\title{
UFTM NEWS: INTERNACIONALIZAÇÃO E APRENDIZAGEM
}

\author{
UFTM NEWS: INTERNACIONALIZACIÓN Y APRENDIZAJE
}

UFTM NEWS: INTERNATIONALIZATION AND LEARNING

\author{
Fernanda de SOUSA ${ }^{1}$ \\ Maíra Sueco Maegava CÓRDULA ${ }^{2}$
}

RESUMO: Esse estudo objetiva averiguar as relações entre as ações do projeto UFTM News, as políticas de internacionalização e a aprendizagem através da análise das interações realizadas nas mídias sociais. Espera-se que as análises comprovem a relevância do projeto na aquisição do inglês e para o processo de internacionalização da UFTM.

PALAVRAS-CHAVE: UFTM News. Internacionalização. Aprendizagem.

RESUMEN: Este estudio objetiva averiguar las relaciones entre las acciones del proyecto UFTM News, las políticas de internacionalización y el aprendizaje por medio del análisis de las interacciones realizadas en las medias sociales. Se espera que los análisis comprueban la relevancia del proyecto en la adquisición del inglés y para el proceso de internacionalización de la UFTM.

PALABRAS CLAVE: UFTM News. Internacionalización. Aprendizaje.

ABSTRACT: This study aims to verify the relationship between UFTM News activities, the internationalization policies and the English language learning process by analyzing the interactions made on social media. It is expected that the analysis confirms the importance of the project in terms of English language acquisition, as well as its contribution to the UFTM- internationalization process.

KEYWORDS: UFTM News. Internationalization. Learning.

\section{Introdução}

${ }^{1}$ Universidade Federal do Triângulo Mineiro (UFTM) - MG - Brasil. Graduanda do curso de Letras Português-Inglês. E-mail: fernanda.sas@ hotmail.com.

${ }^{2}$ Universidade Federal do Triângulo Mineiro (UFTM) - MG - Brasil. Professora Dra. Adjunta de Língua Inglesa e Práticas de ensino de Língua Inglesa. E-mail: mcordula@gmail.com. 
A linguagem é, primordialmente, aquilo que nos distingue dos demais seres. É, segundo o linguista Hjelmslev na abertura de seu livro intitulado Prolegômenos a uma teoria da linguagem (1975), aquilo que cativa aos homens e a base primordial de nossa sociedade, o mais valioso legado que deixamos às próximas gerações. É na língua e pela língua que transmitimos nossos infinitos valores, memórias e emoções, nos constituindo enquanto sujeitos.

Nesse contexto e nesse século, tal conceito jamais se fez tão aplicável. Inseridos em um mundo globalizado e multicultural - o último, especialmente, quando nos referimos ao Brasil -, onde os meios de transporte e comunicação sofreram profundas mudanças (BAUMAN, 1999). Com a internet, por exemplo, as informações deixaram de envolver exclusivamente o movimento de corpos físicos (BAUMAN, 1999), sendo a comunicação a distância em tempo real, em domicílio, com povos de inúmeras nacionalidades por meio de mídias sociais que optam, em grande maioria, pelo inglês como língua franca.

Informações como essas reforçam a proposta de Kachru (1985) no que diz respeito à separação da língua inglesa segundo três círculos de influência: inner circle, para os países cujo inglês atuava como língua materna; outer circle, fazendo parte dele os países que utilizam o inglês como segunda língua por motivos históricos ou culturais; e expanding circle para os demais países que estudam o inglês como língua estrangeira. Sendo assim, por inferência, nosso país faz parte do terceiro círculo, ou seja, reconhecemos o inglês como língua internacional e estudamos esse idioma apesar de não termos, necessariamente, nenhum vínculo colonial por parte de nenhum dos países que têm a língua inglesa como língua materna (inner circle), como veremos posteriormente.

Nota-se que parte desse reconhecimento da língua inglesa enquanto língua internacional foi reforçada com o setor profissional no Brasil nas décadas de 50 e 60, a partir da consolidação de empresas multinacionais (CAPUTO; MELO, 2009). A mudança no mercado de trabalho implicou em novos pré-requisitos nos currículos das próximas gerações. Escolas particulares para o ensino do inglês se alastraram para atender às novas demandas do mercado de trabalho. Isso ocorreu de forma mais enfática, segundo Morosini (2006), com o processo de globalização na década de 90, quando a internacionalização do ensino superior se fortificou.

O apoio governamental definitivo no Brasil veio na década seguinte, através de parcerias entre os departamentos de Cooperação Internacional das instituições com 
universidades estrangeiras $\mathrm{e}$, posteriormente, com os programas nacionais $\mathrm{e}$ governamentais Ciências sem Fronteiras (através do decreto 7642, em 2011) e Idiomas sem Fronteiras (através da portaria 973, em 2014).

Inserido nesse contexto, foi idealizada pelo Núcleo de Línguas da UFTM em parceria com a Assessoria de Cooperação Internacional uma nova estratégia que agiria em prol da internacionalização. Percebendo a necessidade de maior visibilidade das atividades de ensino, pesquisa e extensão desenvolvidos, localmente, surgiu o projeto UFTM News: Tradução de Notícias.

Com a expansão do projeto e a divulgação das atividades realizadas por ele, percebemos que as notícias traduzidas eram de utilidade não apenas para instituições e estudantes estrangeiros, como também dos alunos da UFTM. Nesse momento, percebemos o papel educacional das traduções que, ao mesmo tempo, atuam como uma ponte de comunicação para futuras instituições parceiras, e atendem à demanda dos alunos brasileiros que estão aprendendo inglês à medida que tem contato com aquilo que é desenvolvido dentro de seu próprio ambiente acadêmico.

Esse estudo parte da hipótese de se verificar como o projeto UFTM News pôde contribuir para a aprendizagem da língua inglesa da comunidade UFTM. Para tal, foram feitos levantamentos de dados de forma qualitativa (via Facebook ${ }^{\mathrm{TM}}$ ) e quantitativa (pelo blog) de maneira a: descrever o alcance nacional e internacional das notícias, averiguando sua relevância enquanto estratégia contribuinte para o processo de internacionalização universitária; refletir sobre as implicações do projeto na relação ensino-aprendizagem no que se refere à aquisição da língua inglesa, informalmente, por meio da criação de um input que estimule o seu aprendizado e discutir a relevância da língua inglesa global para a disseminação da cultura local.

Antes de seguirmos com a apresentação do projeto, é fundamental conhecermos o contexto no qual nos inserimos. Nos subtópicos seguintes, discutiremos rapidamente a importância da língua inglesa na atualidade, sob a ótica de dois pontos cruciais: os caminhos trilhados pelo inglês para que assumisse o posto de língua global e como esse fator influencia nas relações universitárias contemporâneas e as linhas gerais que guiaram nosso processo de tradução.

\section{A Expansão}


O inglês, apesar de não ocupar atualmente o topo na categoria de língua mais falada do mundo, tornou-se uma língua global por uma série de fatores. Dois dos principais deles incluem o domínio militar e político que Estados Unidos da América e Inglaterra exerceram e exercem ao longo da história mundial - aspectos esses que, com o passar do tempo, passam a influir em outras esferas: cultural, econômica e tecnológica (CRYSTAL, 2003).

Crystal (2003) apresenta alguns momentos históricos importantes que contribuem para que a língua inglesa tenha o status de língua global na atualidade. $\mathrm{O}$ status alcançado por essa língua se deu, primeiramente, pela Inglaterra e em número considerável no período Elizabetano, quando as expedições inglesas aportaram na costa norte-americana e nas ilhas próximas, realizando a colonização de povoamento.

Nas expedições marítimas, comerciantes ingleses estabeleceram ao sul da Índia, com o consentimento da rainha, um monopólio conhecido como Companhia Britânica das Índias Orientais, ficando responsável pelo comércio, a nível mundial, de produtos como algodão, chá, ópio, sal e seda. O inglês passa, consequentemente, a ser alvo de discussões e estratégias de implementação nos séculos seguintes - atingindo ao status de língua associada oficial na atualidade (CRYSTAL, 2003).

Ao longo do século XVIII, uma série de migrações flexibilizaram a prosódia e as relações sociolinguísticas inglesas em terras norte-americanas (CRYSTAL, 2003). Houve, também, a exportação de prisioneiros britânicos para a primeira colônia penal em Sidney, Austrália. Os ingleses instalaram, ainda, suas primeiras colônias na Nova Zelândia em meados do século XIX, através de suas campanhas missionárias. Ao início desse mesmo século, a Inglaterra se acomodou em diversos países africanos, estabelecendo-se a língua inglesa, com o passar do tempo, como oficial. Apesar de não ter se espalhado por todo o continente, se tornou o segundo idioma falado pelos africanos em diversas regiões seja por fatores históricos, sócio-políticos ou devido ao hibridismo étnico resultante das colonizações.

Conforme David Crystal (2003), o inglês conquistou também terras ao sudeste da Ásia e ao sul do Pacífico através, primeiramente, das expedições do Capitão Cook e, dois séculos depois, com os ataques norte-americanos às ilhas japonesas durante a Segunda Guerra Mundial. A predominância dos Estados Unidos da América a partir da criação das três instituições responsáveis pela economia mundial ao final do século XX (MOITA LOPES, 2008), ocasionou numa nova fase comumente conhecida como neocolonialismo ou imperialismo e foi um dos principais fatores associado às mudanças 
que fizeram com que a língua se estabilizasse em diversos países, migrando para uma série de setores - dentre eles, dois que vêm ganhando bastante destaque desde então: o educacional e o profissional.

\section{A Internacionalização das IES}

Qiang (2003) destaca que ao final da Segunda Guerra Mundial, as ações de internacionalização eram focadas especialmente:

[...] em objetivos humanitários de melhorar a compreensão entre pessoas para uma coexistência pacífica e, posteriormente, em solidariedade a países que não faziam parte do mundo industrializado. Cada vez mais, entretanto, as preocupações relacionadas à competência e competitividade internacional e, assim, a lógica econômica, torna-se mais importante. Considerase que os mercados internacionais de trabalho exigem que o sistema de ensino superior entregue graduados com qualificações acadêmicas, linguísticas e interculturais internacionalmente competitivas ${ }^{3}$. (QIANG, 2003, p. 251)

Nota-se, portanto, que devido às constantes demandas das sociedades globalizadas no que se refere à economia e ao mercado de trabalho, houve a necessidade de adequação e preparação a esse novo modelo para as gerações seguintes. A relação entre o ensino e a internacionalização se dá, em diversos casos, através de pesquisas e publicações que se dão em língua inglesa - segundo Rajagopalan, "em torno de 80 a $90 \%$ da divulgação do conhecimento científico ocorre em inglês" (2005, p. 149). É também o que aponta Moita Lopes (2008, p. 311) quando diz que "a ânsia de fomentar publicações internacionais, em algumas universidades, pontua diferentemente e, na verdade, remunera, de forma distinta, pesquisadores que publicam em inglês e na língua nacional", sendo esse outro fator essencial que reforça a necessidade da língua estrangeira na contemporaneidade.

Foi baseando-se em ideias como essas que surgiram dois programas nacionais e governamentais: Ciências sem Fronteiras e Idiomas sem Fronteiras. Conforme consta no documento redigido em 2012 pela Andifes (Associação Nacional dos Dirigentes das

\footnotetext{
${ }^{3}$ No original, em inglês: “(...) on humanitarian aims of improving understanding between people for peaceful coexistence, and, later on, on solidarity with countries in the non-industrialized world. Increasingly, however, concerns related to international competence and competitiveness, and thus the economic rationale, becomes more important. It is felt that international labour markets require the higher education system to deliver graduates with academic, linguistic and intercultural qualifications that are internationally competitive" (QIANG, 2003, p. 251).
} 
Instituições Federais de Ensino Superior), a continuidade da política de expansão das universidades deve enfatizar: um novo contexto global, com mão de obra que seja capaz de atender às necessidades econômicas e sociais, sem descartar os padrões atuais de sustentabilidade; a produção de uma "nova ordem mundial do conhecimento" (ANDIFES, 2012: 6), na qual se produza ciência, tecnologia e inovação. Ainda, segundo o mesmo documento, o governo brasileiro afirma a necessidade de gerar e difundir conhecimentos tecnológicos no país emergente e as IES desempenham, nesse viés, um papel primordial.

Através do decreto n 7642 de dezembro de 2011, se instituiu o Ciências sem Fronteiras, se definindo como um programa cujas ações são "complementares às atividades de cooperação internacional” (BRASIL, 2011, p. 1) e que busca, resumidamente, propiciar novas experiências educacionais e profissionais "voltadas para a qualidade, o empreendedorismo, a competitividade e a inovação em áreas prioritárias e estratégicas para o Brasil" (BRASIL, 2011, p. 1), ampliando a mobilidade internacional dos participantes para desenvolver treinamentos, projetos, estudos e capacitação em universidades estrangeiras. Por conseguinte, promovem-se a cooperação internacional, as produções e pesquisas técnico-científicas e a competitividade das empresas nacionais e internacionais.

Com a vigência do programa, o governo percebeu, entretanto, que muitos dos candidatos "não se qualificavam para o programa por terem um nível baixo de proficiência em inglês" (FONSECA, 2006). Para enfrentar o novo obstáculo, implementou-se o programa Idiomas sem Fronteiras, por meio da portaria de $\mathrm{n}^{\mathbf{0}} 973$, ao final de 2014, sendo ele "complementar às atividades do Programa Ciências sem Fronteiras e de outras políticas públicas de internacionalização da educação superior" (fl.73). O programa ofereceu cursos online para milhões de universitários e promoveu a criação de Núcleos de Línguas (NucLis) para cada Instituição de Ensino Superior (IES). Cada NucLi, com o auxílio dos coordenadores geral e pedagógico, ficou responsável pela seleção e treinamento dos professores de língua inglesa. O programa ainda permitiu que fossem realizados, gratuitamente, o TOEFL ITP, exame de proficiência e nivelamento aceito por universidades em várias partes do mundo para a admissão em programas acadêmicos.

Pensando no caráter difusivo da proposta feita pela Andifes, imaginou-se um novo projeto, aplicável ao contexto local da universidade, o UFTM News: Tradução de Notícias, com o intuito de dar visibilidade às ações e aos serviços realizados por todos 
os cursos da universidade e, simultaneamente, contribuir para as ações de internacionalização da IES.

\section{Os procedimentos da tradução jornalística}

Falar em tradução ${ }^{4}$ implica um grande arcabouço de temáticas e áreas de atuação. Há vários tipos de tradução e inúmeros procedimentos para fazê-la, portanto, fecharemos o escopo para abordamos aquilo que faz parte de nosso projeto: a tradução de textos jornalísticos, mais especificamente, o gênero notícia.

Conforme explicitam Zipser e Polchlopek (2009, p. 2), a tradução consensual se define “como 'aquela "fiel à letra', como transcodificação isenta e que se propõe objetiva, imparcial e neutra no relato do fato jornalístico, como convém aos princípios éticos que regem a imprensa". Ambas as atividades, tradução e jornalismo, são iguais no almejo pela imparcialidade, sendo os profissionais da área por vezes descritos como mediadores, pontes entre a informação e a linguagem. Ainda segundo Zipser e Polchlopek (2009, p.4) as duas práticas:

[...] reúnem a combinação da prática acadêmica com a reflexão teórica, sistematizando fatores de influência para ambas as áreas à luz do conceito de interculturalidade, o qual pressupõe uma interação e enriquecimento mútuos entre diferentes sociedades.

Diante da tarefa de versar para a língua inglesa as notícias acadêmicas, a equipe embasou-se, principalmente, nos treze procedimentos básicos de tradução propostos por Barbosa (2004, p. 64), sendo eles:

[...] a tradução palavra-por-palavra, a tradução literal, a transposição, a modulação, a equivalência, a omissão vs. a explicitação, a compensação, a reconstrução de períodos, as melhorias, a transferência - que engloba o estrangeirismo, a transliteração, a aclimatação e a transferência com explicação - a explicação, o decalque e a adaptação.

Dessa maneira, os métodos mais utilizados ao longo desse projeto foram:

a) A tradução literal, apenas com pequenas alterações morfossintáticas, tentando manter ao máximo a lealdade semântica dos termos da notícia e, também, para que fosse

\footnotetext{
${ }^{4}$ Neste trabalho, utilizamos o termo tradução de forma ampla, incluindo no mesmo termo tanto a tradução
} quanto a versão. 
possível a comparação do texto traduzido com o original, visto o caráter bilíngue da atividade (BARBOSA, 2004).

b) A transposição, que consiste em elementos modificados gramaticalmente, a fim de tornar o texto em português visualmente mais harmônico.

c) Explicitação e repetição de termos, visto que, em inglês a presença de um sujeito na sentença é sempre mandatória.

d) A reconstrução de períodos, dividindo e reagrupando orações ora por motivos estilísticos, ora devido às construções complexas que o português apresenta e que podem ser simplificadas, tornando a leitura mais fácil.

e) A transferência com explicação devido à grande quantidade de nomes de instituições e siglas como, por exemplo, CAPES, HC-UFTM, $\mathrm{ACI}^{5}$ que podem não ser compreendidas pelos leitores estrangeiros. Partimos do princípio que, caso venham a frequentar a UFTM, esses estudantes entendam não só o significado dessas instituições com a tradução dos termos para a língua inglesa - como possam se localizar geograficamente a partir dos nomes originais, dado que os sistemas universitários são globalmente distintos.

Com essas perspectivas determinadas, apresentamos alguns dos procedimentos da tradução e as ferramentas digitais de tradução disponíveis (além de como utilizá-las apropriadamente) aos participantes das oficinas de treinamento, que poderiam utilizar dos conhecimentos adquiridos ao participar voluntariamente do UFTM News. Nas oficinas, emergiram também outras questões ligadas aos procedimentos de tradução, como um levantamento das dificuldades mais constantes ao tradutor ao lidar com textos de vertente acadêmica (como, por exemplo, a tradução de nomes de instituições), a função exercida pelas notícias traduzidas e a valorização do tradutor no mercado de trabalho contemporâneo.

\section{Metodologia}

O projeto de extensão UFTM News: Tradução de Notícias teve início em março de 2016, consistindo na tradução de notícias oficiais do site da UFTM voltadas às

\footnotetext{
${ }^{5}$ Respectivamente: Comissão de Aperfeiçoamento de Pessoal do Nível Superior (CAPES); Hospital de Clínicas da UFTM (HC-UFTM) e Assessoria de Cooperação Internacional (ACI).
} 
atividades acadêmicas, da língua portuguesa para a inglesa. Não passa despercebido, por sua vez, a noção de que o inglês:

[...] devido ao seu alcance global, uma possibilidade de ter acesso a outros discursos sobre o mundo e sobre quem somos ou podemos ser, sendo, portanto, um veículo para construir uma outra globalização com base nos interesses de seus falantes. (MOITA LOPES, 2008, p. 318)

Assim, a partir do domínio da língua inglesa que possuímos, passamos a nos servir dele para expor um complexo cultural e educacional ainda desconhecido aos demais falantes fora do território brasileiro, trazendo ao processo globalizado as narrativas de nosso conhecimento local (MOITA LOPES, 2008).

Para executar essa tarefa, a equipe se compôs pela Dra. Maíra Sueco Maegava Córdula, responsável pela coordenação do projeto; pela professora do curso de Letras Dra. Carla Regina Rachid Otavio Murad, vice coordenadora e revisora do projeto; pela tradutora da Assessoria de Cooperação Internacional da UFTM, Ma. Maria Teresa Marques Santos, revisora e ministrante das oficinas; e pela graduanda Fernanda de Santana Alves de Sousa, responsável pela tradução e edição das notícias do blog.

O levantamento das notícias a serem traduzidas se deu considerando aspectos como a data da notícia, o seu caráter local, e a divulgação de ações, projetos e cursos realizados pela comunidade UFTM. Nos objetivos específicos do projeto estavam:

1) Traduzir 15 notícias do site oficial da UFTM para a língua inglesa; 2) Levantar temas e dificuldades de tradução recorrentes nas notícias traduzidas; 3) Preparar instrumento para revisão/edição entre pares de tradução de notícias; 4) Registrar os comentários dos leitores das notícias em quantidade de comentários positivos e negativos; 5) Registrar o número de comentário de leitores de acordo com a temática noticiada em língua estrangeira. (CORDULA et. al., 2016, p. 5) ${ }^{6}$

Uma das ações de enfoque do projeto era, portanto, a preparação de oficinas para que os alunos do curso de Letras pudessem integrar-se ao projeto, desenvolvendo e conhecendo técnicas de tradução específicas para atender à demanda. Ofertaram-se, ao todo, quatro oficinas nas quais discutiram-se e realizaram-se os processos de tradução sob a supervisão da tradutora Ma. Maria Teresa, bem como a discussão de temas já

${ }^{6}$ Projeto de extensão homologado ao Sistema de Informação e Gestão de Projetos (SIGProj), inscrito pelo número 223258.1104.245164.24012016, edital nº13/2015. 
citados. Houve, ao longo de todo o desenvolvimento do projeto, encontros mensais da equipe nuclear nos quais se definiam os próximos passos a serem tomados.

Parte do projeto consistia, ademais, na divulgação e apresentação das notícias. Para isso, escolhemos uma página no Facebook ${ }^{\mathrm{TM}}$ e o blog próprio UFTM News $(2016)^{7}$. Esse trabalho se deu da seguinte forma: as notícias traduzidas ficaram disponíveis em um documento, numa pasta compartilhada no Google Drive ${ }^{\mathrm{TM}}$, garantindo acesso a todas as integrantes. Após uma revisão minuciosa, os textos eram encaminhados ao blog do projeto, editados, devidamente postados e categorizados segundo a sua área temática (curso) e de atuação (pesquisa, ensino e/ou extensão).

Com a postagem no blog, fez-se, ao início do mês de agosto, a divulgação através da página do Facebook ${ }^{\mathrm{TM}}$ a partir de um trecho da notícia em português e inglês e o link que direcionava os interessados, para a notícia completa disposta no blog. Ao final de cada notícia se encontravam disponíveis os links dos textos originais em português brasileiro, de maneira que os leitores com mais dificuldade pudessem compreender, com auxílio, o conteúdo apresentado e que aqueles interessados no processo de tradução pudessem compreender as estratégias adotadas pela equipe.

Propomo-nos, então, a fazer dois tipos de análise:

a) Quantitativa, com as estimativas oferecidas pelo próprio sistema de gestão de página do Facebook ${ }^{\mathrm{TM}}$, apontando: o número total de curtidas, comentários e compartilhamentos das notícias divulgadas, bem como a localidade em que se encontram as pessoas alcançadas pelas divulgações e suas faixas etárias num período máximo de 28 dias. O sistema apura, ainda, o dia e horário da semana em que a página é mais movimentada, a estimativa média de acessos por dia e o número de acessos por notícia publicada.

b) Qualitativa, com a criação do feedback, uma subseção no blog que contém um questionário, com quatro perguntas, destinado a acolher comentários e sugestões dos leitores.

\section{Análise quantitativa}

7 Cujos endereços eletrônicos são, respectivamente: www.facebook.com/UftmNews/ e www.uftmnews.wordpress.com 
Foram publicadas e divulgadas 17 notícias conforme os procedimentos já citados. Nosso objetivo específico, que era ter 15 notícias traduzidas em língua inglesa, foi alcançado. O número de curtidas na página foi de 124 ao término da coleta, porém, o alcance foi variável de acordo com o mês, por isso os resultados foram divididos por períodos de 28 dias cada $^{8}$.

Como é possível ver no resumo geral da página no período de 06 agosto a 02 de setembro, as publicações alcançaram 3.254 pessoas, sendo que dessas, 83 se encontram em território internacional: 24 no Peru, 20 na França, 12 nos Estados Unidos, 4 no Canadá, 3 no Reino Unido, 2 nos Emirados Árabes Unidos, 2 na Itália, 2 no Marrocos, 2 na Alemanha, 1 na Bélgica, 1 na Suécia, 1 na Holanda, 1 na Nigéria, 1 no Kuwait, 1 na China, 1 no México, 1 em Nepal, 1 na Austrália, 1 na Argélia, 1 na Tunísia e 1 na Índia. A página, naquele instante, possuía 111 curtidas e uma média de 106 visualizações diárias. As notícias com maior acesso são relativas as áreas: da saúde, intitulada $H C$ UFTM: itinerant action provides exams and guidance to the community (HC-UFTM: ação itinerante levou exames e orientações à comunidade); e de engenharia, intitulada UFTM Robotics Tournament attracts competitors from the region (Torneio de Robótica da UFTM atrai competidores da região).

Já no resumo geral da página no período de 15 de setembro a 13 de outubro houve uma queda para 1.082 pessoas alcançadas pelas publicações, sendo que dessas, apenas 8 se encontram em território internacional: 3 na França, 1 na Alemanha, 1 na Austrália, 1 na Itália, 1 na Bolívia e 1 nos Estados Unidos da América. A página, naquele momento, possuía 115 curtidas e uma média de aproximadamente 110 visualizações diárias. As notícias de maior acesso foram relativas: novamente, a área de saúde, intitulada HC-UFTM takes exams and guidance to Lourdes neighborhood (HCUFTM levou exames e orientações ao bairro de Lourdes); e a área de Geografia, intitulada UFTM Geography course student's end of course paper is awarded in technology exhibition dedicated to drones (TCC de aluno do Curso de Geografia da UFTM é premiado em exposição de tecnologia dedicada a drones).

Entre 14 de outubro e 10 de novembro houve, novamente, uma queda para 823 acessos às publicações, sendo dessas 5 em território internacional: 3 em Honduras, 1 na Suécia e 1 na Índia. Naquele momento, a página possuía 128 curtidas e uma média de aproximadamente 124 visualizações diárias. As notícias de maior acesso tinham como

8 As informações aqui disponibilizadas podem ser também acessadas através do link <http://www.uftmnews.wordpress.com/interacoes-realizadas-na-pagina/>. 
temática as áreas: da saúde, com a notícia intitulada Thematic Week debates emotional health and learning (Semana Temática debate saúde emocional e aprendizagem) e de Engenharia, com a notícia UFTM and French university sign double degree agreement (UFTM e universidade francesa assinam acordo de dupla diplomação).

Observa-se o interesse maior dos leitores pelas notícias relativas à Saúde e à Engenharia, seguidos por Geografia, Letras, Psicologia e Biologia. Acompanhando os países atraídos pelo projeto, percebemos que as notícias locais entraram em contato com o público estrangeiro. Simultaneamente, entendemos que tivemos uma quantidade de acesso satisfatório, tendo em vista que, ao longo dos meses de divulgação, uma média estável de 115 pessoas teve contato diário com as notícias e, consequentemente, com a língua inglesa.

Resultados como esses frisam a importância do projeto desenvolvido e confirmam a ideia de Moita Lopes (2008) e Rajagopalan (2005) de que o inglês passa a servir aos nossos interesses locais, enquanto cumpre também seu papel comunicativo e informacional - passando a integrar o que Rajagopalan chama de World English. Tais conceitos retornarão, também, na análise qualitativa.

\section{Análise qualitativa}

A análise qualitativa, conforme descrita no item 2, consistiu em um questionário, publicado no blog do projeto, aberta para todo o público. As seguintes questões foram colocadas, tanto em inglês quanto em português:

1) O que gostou no blog?

2) Você tinha conhecimento prévio acerca da notícia a qual teve acesso?

3) Aprendeu alguma palavra nova? Qual (ais)? Ela está relacionada a sua área de atuação?

4) Quais seriam as próximas notícias que você gostaria de ver aqui?

Obtivemos doze respostas ao longo dos meses de divulgação e, com elas, pudemos analisar uma série de aspectos do projeto por uma segunda perspectiva: a do leitor. O estudo feito aqui foi fundamentado pelos comentários apresentados nessa sessão do blog e, para facilitar a compreensão, dividido nos seguintes sub tópicos que abordaram os aspectos suscitados por cada questão: 1) língua, internacionalização e 
aprendizagem; 2) funções da linguagem; 3) léxico e tradução: uma relação harmoniosa e 4) relevância.

\section{Língua, internacionalização e aprendizagem}

Com a primeira pergunta, foi possível captar a recepção do trabalho desenvolvido por toda a equipe. Todos os comentários foram positivos. A organização estrutural e visual do blog foi um aspecto destacado entre três dos comentários. A grande maioria dos comentários parabenizou a iniciativa, considerando-a importante enquanto integrante do processo de internacionalização. Seguem alguns trechos:

(1) "É uma ideia simples e fantástica para mostrar ao mundo a comunidade acadêmica da UFTM e do Brasil, e que estamos abertos a comunicação e troca de experiências com outras culturas. " (Leitor $\left.1^{9}\right)$

(2) "Achei muito interessante, principalmente pelo fato de termos agora as traduções para o inglês para a expansão da universidade. '”

(Leitor 4)

(3) "O blog auxilia na divulgação das notícias para estrangeiros.

$(\text { Leitor } 7)^{10}$

Com os comentários 1, 2 e 3 é possível notar que os leitores compreendem e apoiam a ideia de se usar a língua dominante como um meio de se divulgar a cultura local acadêmica. Novamente, comprovamos a existência e necessidade do World English (RAJAGOPALAN, 2005), que dá visibilidade a um mundo inicialmente desconhecido ou que não tinha sido experimentado por aqueles que têm inglês como língua materna e muitas vezes não demonstrariam interesse em aprender uma outra língua que não seja a sua (CRYSTAL, 2003).

Em outras respostas a essa mesma pergunta, tivemos:

(4) “[...] os leitores podem ter acesso tanto ao conteúdo em outra língua (Inglês) quanto ao conteúdo em Português, podendo assim

${ }^{9}$ Os leitores serão identificados por números.

${ }^{10}$ Segundo as normas da ABNT, as palavras estrangeiras devem vir em itálico. Entretanto, os excertos que aqui aparecem são de comentários do blog, de maneira que se preferiu, nesse caso, manter a formatação e ortografia utilizada pelos leitores. 
treinar seu inglês e seu vocabulário ao mesmo tempo em que se atualiza sobre as notícias acadêmicas da UFTM." (Leitor 3)

(5) “[...] possibilitando [o blog] não só ficar por dentro dos eventos, projetos e ações estudantis que ocorrem na UFTM, como também treinar o inglês e aumentar o vocabulário no mesmo, de um modo objetivo e produtivo." (Leitor 9)

Em respostas como essas percebemos, primeiramente, que é possível aprender inglês através da leitura das notícias. A evidência se dá ao notarmos que uma quantidade considerável dos comentários a essa pergunta incluiu o verbo "aprender" como resposta. Lightbown e Spada (1998, p. 26) corroboram essa observação ao afirmarem que: "o aprendiz não precisa falar ou escrever para, de fato, adquirir a linguagem. A aquisição acontece internamente à medida que eles leem ou ouvem amostras da linguagem que entendam" ${ }^{11}$. As notícias geram um input que interage com o contexto no qual os leitores se encontram (estudantes universitários de um determinado curso), sendo elas apropriadas ao seu atual estágio de competência linguística. Salientamos, porém, que não há evidências suficientes nos comentários para que possamos afirmar que esse processo é definitivo ou qual seria o seu nível de efetividade.

Outro aspecto notável, ainda, é a importância da língua portuguesa enquanto suporte para a leitura das notícias em inglês. Conforme apontam Lightbown e Spada (1998, p. 25):

“[...] a influência da língua nativa do aprendiz não se reduz a um problema habitual, mas de um processo muito mais complexo e sutil de identificar pontos de similaridade, pesar a evidência que dá suporte a uma característica particular, e até mesmo refletir (ainda que não necessariamente de forma consciente) sobre a possibilidade de uma certa característica 'pertencer' a uma estrutura da língua alvo"12.

A partir do acesso ao link disponibilizado ao final das notícias em inglês à notícia original, os leitores têm a oportunidade de fazer uma análise comparativa de

${ }^{11}$ No original, em inglês: "(...) the learner need not actually speak or write in order to acquire language. Acquisition takes place internally as learners read and hear samples of the language that they understand" (LIGHTBOWN \& SPADA, 1998, p.26).

${ }^{12}$ No original, em inglês: “(...) the influence of the learner's first language is not simply a matter of habits, but a much more subtle and complex process of identifying points of similarity, weighing the evidence in support of some particular feature, and even reflecting (though not necessarily consciously) about whether a certain feature seem to 'belong' in the structure of the target language." (LIGHTBOWN \& SPADA, 1998:25) 
vocabulário e estrutura, compreendendo, decifrando e avaliando melhor o significado contextualizado de determinadas escolhas lexicais.

\section{As funções da linguagem}

Com a segunda pergunta (Você tinha conhecimento prévio acerca da notícia a qual teve acesso?), foi possível avaliar quais as funções exercidas pelas notícias. A tradução é um trabalho metalinguístico, considerando-se que o tradutor codifica e decodifica textos da língua de origem (source language) para a língua-alvo (target language). A partir dos comentários de alguns leitores notamos, entrementes, que as traduções realizadas exerceram uma segunda função. Seguem os excertos:

(8) "Eu não possuía conhecimento prévio desta notícia e fiquei muito feliz em saber que nossa universidade realizou um torneio como esse [...]." (Leitor 9)

(9) "Apenas 1 das notícias que eu li eu já tinha conhecimento prévio, por ser relativo ao meu curso. Sobre as demais notícias lidas, eu não tinha conhecimento prévio." (Leitor 11)

Oito dos doze leitores que responderam ao questionário afirmaram não ter conhecimento prévio das notícias as quais tiveram acesso. $\mathrm{O}$ fato desses leitores não possuírem nenhum contato anterior com a notícia faz com que a tradução exerça a função referencial - e essencial ao gênero jornalístico -, de informar.

\section{Léxico e tradução: uma relação harmoniosa}

Ao responderem à terceira questão (Aprendeu alguma palavra nova? Qual (ais)? Ela está relacionada a sua área de atuação?), foi possível fazermos um levantamento lexical daquilo que representou alguma dificuldade, estranhamento ou interesse aos leitores.

(11) "Conheci palavras novas como Enterprise e outskirt. Sendo a primeira relacionada a minha área." (Leitor 3)

(12) "Sim, outpatient treatment, guidance. Não está relacionada à minha área de atuação" (Leitor 7) 
(13) "Sempre fiquei pensando em como se traduzia o "curso de letras". Pensava em algo mais dificil ou elaborado [...]." (Leitor 1)

É inevitável que reflitamos sobre quais os possíveis motivos para que essas palavras se repitam entre os comentários. Dentre as palavras citadas estão: outskirt (2), outpatient (2), guidance (2), Letters Course (2), permaculture (1), groceries (1), sponsorship (1), trolley (1), undergraduates (1), alignment (1), ensuring (1) e fruitful (1). Por não podermos nos estender muito, faremos, então, um recorte para as palavras de maior ocorrência.

A morfologia da primeira palavra pode ter um relacionamento forte com o seu desconhecimento: outskirts, pode ser considerada uma palavra de composição inusitada out (fora) + skirts (saias). Há ainda, a comparação média de usuários que a utilizam em paralelo a outra palavra que lhe é sinônima: suburbs. Segundo o levantamento realizado pelo site Corpus of Contemporary American English ${ }^{13}$ (COCA, doravante), outskirts possui uma frequência de 20.835, enquanto suburbs ocorrerá 29.505 vezes. Apesar de não haver uma grande diferença entre as ocorrências, ela não deixa de ser de um valor considerável.

Outra palavra que também possui uma composição incomum, novamente partindo-se da junção de um advérbio (out) com um substantivo (patient) é outpatient. A frequência da palavra no COCA é de 5147, sendo que a grande maioria de suas ocorrências estão em revistas, artigos, notícias e documentários relacionados a área de saúde. Como aqueles que apontaram essa palavra não pertencem a esse campo de estudo, o desconhecimento do termo é justificável.

Dois dos leitores apontaram guidance como uma palavra desconhecida até então. Aqui, diferente de sua composição, de sua frequência (que é alta, cerca de 56.580 ocorrências), ou até mesmo de sua ligação a um campo semântico específico - uma vez que essa palavra pode ser empregada em diversos contextos -, a maior probabilidade para o estranhamento se dá pelo fato de que as versões dessa mesma palavra em inglês e em português são bastante distintas, não possuindo nenhum radical ou afixo em comum.

Duas leitoras deram em suas respostas a frase nominal Letters Course, fato curioso, visto que, pelo comentário completo de cada uma, elas possivelmente são estudantes do curso de Letras e/ou têm um contato frequente com o curso. Essa dúvida

\footnotetext{
${ }^{13}$ Endereço eletrônico do site: 〈www. corpus.byu.edu/coca/>.
} 
nos apresenta cenários interessantes e o primeiro deles tem relação com o fato de que, até o presente momento, existem poucas atividades de tradução incorporadas ao currículo do curso da instituição, o que ocasiona em eventuais dúvidas ligadas à vocábulos pertencentes a essa área.

Um segundo cenário é o da correspondência de significado entre as traduções. Para o termo "curso de Letras" há as expressões: Languages Degree (segundo a Universidade de Surrey), Language and Literature Degree (segundo a Universidade de Harvard) e Linguistics Degree (encontrado em diversos artigos científicos). Nenhum dos termos indicados, contudo, é capaz de expressar em totalidade o conteúdo representativo ao curso oferecido pela UFTM, visto que a grade curricular engloba todas as grandes áreas citadas anteriormente, juntamente às disciplinas didáticas. Ao traduzirmos, achamos os nomes comumente apresentados insuficientes para apreender o sentido total do curso, de maneira que, a sua tradução mais literal pareceu a melhor codificação. Aqui, voltamos ao conceito de World English de Rajagopalan (2005) e fazemos uso de um inglês que, apesar de não ser considerado típico aos falantes nativos, existe e cabe aos propósitos locais.

\section{Relevância das traduções}

Finalmente, os leitores listaram quais seriam as próximas notícias que gostariam de ver. Percebeu-se um grande interesse por parte dos leitores pelos eventos institucionais, os programas sociais e culturais, os trabalhos e pesquisas científicas realizadas na IES.

Ao serem solicitadas temáticas para as próximas notícias, evidenciou-se a relevância do projeto desenvolvido à comunidade acadêmica da UFTM, que passa a acompanhar o trabalho realizado, fazendo uso dele para propósitos próprios (conforme indicado pelos comentários: treinar o inglês, expandir o vocabulário, refletir sobre a expansão da instituição, se informar sobre o que acontece no meio acadêmico). Estamos, por conseguinte, participando da infusão de dimensões internacionais e interculturais às políticas de internacionalização da instituição superior (KNIGHT, 2003), ao atendermos às demandas locais, expomos as diversas atividades desenvolvidas pela universidade para outras IES enquanto buscamos, simultaneamente, facilitar possíveis parcerias estrangeiras. 


\section{Considerações finais}

O projeto UFTM News, ao longo de seus nove meses de desenvolvimento, incorporou-se, ainda que em menor escala se comparado a programas como Ciências sem Fronteiras e Idiomas sem Fronteiras, às políticas de internacionalização da UFTM. A partir das traduções e divulgações, solucionamos um obstáculo que, por vezes, pode impedir o estreitamento de laços entre as nações: a língua. Com UFTM News, as instituições de ensino estrangeiras e os estudantes interessados podem compreender melhor o funcionamento da UFTM, possibilitando parcerias que, segundo Fonseca (2016: 26) "proporcionam o intercâmbio de ideias, pesquisas inovadoras e soluções para problemas mais complexos, o que impacta diretamente a qualidade das experiências acadêmicas".

Ainda que não possamos afirmar, conforme dito anteriormente, qual é o nível preciso de aprendizado de nossos leitores ao terem contato com nosso blog, não podemos ignorar os comentários feitos por aqueles que afirmam ter assimilado alguma palavra e que veem nas notícias uma oportunidade de "praticar o inglês". Ao que concerne à relação do projeto com o ensino, podemos dizer, portanto, que os resultados apontam o potencial educacional do UFTM News e a necessidade de se pesquisar mais sobre a aprendizagem de línguas em contextos informais de relevância local, canalizados pelas mídias sociais, como o contexto oferecido pelo projeto de extensão.

O projeto serviu, por fim, como um mediador que demonstra que "as pessoas podem dar outros destinos aos designs globais (ao inglês e aos discursos que essa língua faz circular) e colocando em questionamento as distinções entre centro e periferia, ao mostrar que o centro pode estar na periferia assim como a periferia no centro" (MOITA LOPES, 2008, p. 331). Enquanto abrimos portas aos alunos e instituições estrangeiras, apresentando-lhes parte de nossa cultura, asseguramos uma fonte de informação e prática da língua inglesa contextualizada aos acadêmicos brasileiros.

\section{REFERÊNCIAS}

ANDIFES (2012). Programa de expansão, excelência e internacionalização das universidades federais. Disponível em: <www.andifes.org.br/wpcontent/files_flutter/1360930928PEEXIU.pdf>. Acesso em: 07 out. 2016.

BARBOSA, H. G. Procedimentos técnicos da tradução. 2 ed. Campinas, São Paulo: Pontes, 2004. 
BAUMAN, Z. Globalização: as consequências humanas. Rio de Janeiro: Jorge Zahar Ed., 1999.

BRASIL. Decreto $n^{0} 7642$, de 13 de dezembro de 2011. Institui o Programa Ciência sem Fronteiras. Diário Oficial da União, Brasília, DF, 13 dez. 2011. 7p. Disponível em: <www.cienciasemfronteiras.gov.br/documents/214072/5058435/Decreto7642Csf.pdf $>$. Acesso em: 07 out. 2016.

BRASIL. Ministério da Educação. Institui o Programa Idiomas Sem Fronteiras e dá outras providências. Portaria $\mathrm{n}^{\circ}$ 973, de 14 de nov. de 2014. Diário Oficial da União, Brasília, DF, 17 de nov. de 2014. fls. 73-76. Disponível em:

<www.isf.mec.gov.br/ingles/images/pdf/novembro/Portaria_973_Idiomas_sem_Frontei ras.pdf >. Acesso em: 07 de out. 2015.

CAPUTO, A. C.; MELO, H. P. A industrialização brasileira nos anos de 1950: uma análise da instrução 113 da SUMOC. Estudos Econômicos, vol. 39, nº3. São Paulo, 2009. p.513-538. Disponível em:

$<w w w . s c i e l o . b r / s c i e l o . p h p ?$ script=sci_arttext\&pid=S0101-

$41612009000300003 \& \operatorname{lng}=$ pt\&nrm=iso\&tlng=pt $>$. Acesso em: 05 out. 2016.

CÓRDULA, M. S. M.; MURAD, C. R. R. O.; SANTOS, M. T. M.; SOUSA, F. S. A. UFTM News: Tradução de Notícias. Anais da II Jornada Integrada de Ensino, Pesquisa e Extensão da Universidade Federal do Triângulo Mineiro. Uberaba: UFTM, 2016. 780p. Disponível em: <http://www.jiepeuftm.com.br/anais16>. Acesso em: 05 out. 2016.

CRYSTAL, D. English as a global language. 2ed. United Kingdom: Cambridge University Press, 2003. Disponível em: <www.culturaldiplomacy.org/academy/pdf/ research/books/nation_branding/English_As_A_Global_Language__David_Crystal.pdf $>$. Acesso em: 17 set. 2016.

FONSECA, A. L. S. B. Inglês: a língua da internacionalização. Interfaces Científicas, Aracaju, n. 2, v. 4, p. 23-32, 2016. Disponível em: <www.periodicos.set.edu.br/index. php/educacao/article/viewFile/3023/1634>. Acesso em: 17 set. 2016.

HJELMSLEV, L. Prolegômenos a uma teoria da linguagem. São Paulo. Perspectiva, 1975.

KACHRU, B. B. Standards, codification and sociolinguistic realism: the English language in the outer circle. In: QUIRK, R.; WIDDOWSON, H. G. (Org.). English in the world. 1 ed. Cambridge: Cambridge University Press, 1985. p. 11-30.

KNIGHT, J. Updated definition of internationalization. In: International Higher Education, $n^{\circ} 33$. Chestnut Hill, M. A: The Boston College Center for International Higher Education, 2003, p. 2-3. Disponível em: <www.ejournals.bc.edu/ojs/index.php/ ihe>. Acesso em: 05 jun. 2016.

LIGHTBOWN, P. M.; SPADA, N. How languages are learned. 3 ed. Oxford: Oxford University Press, 1998. 135p. Disponível em: <www.passeidireto.com/arquivo/213723 51/how-languages-are-learned-3rd-edition-242-pages-2006>. Acesso em: 22 nov. 2016. 
MOITA LOPES, L. P. Inglês e globalização em uma epistemologia de fronteira: ideologia lingüística para tempos híbridos. In: DELTA, São Paulo, v. 24, nº . 2, 2008. p. 309-340. Disponível em: <www.scielo.br/scielo.php?script=sci_arttext\&pid=S01024450200800 0200006>. Acesso em: 01 out. 2016.

MOROSINI, M. C. Estado do conhecimento sobre internacionalização da educação superior: conceitos e práticas. In: Educar, Curitiba, $\mathrm{n}^{\circ}$. 28, p.107-124, 2006. Disponível em: <www.dx.doi.org/10.1590/S0104-40602006000200008>. Acesso em 03 out. 2016.

QIANG, Z. Internationalization of higher education: towards a conceptual framework. In: Policy futures in education. vol. 1, no. 2. SAGE Publications: 2003. p. 248-270. Disponível em: <www.pfe.sagepub.com>. Acesso em: 30 de set. 2016.

RAJAGOPALAN, K. A geopolítica da língua inglesa e seus reflexos no Brasil. In: LACOSTE, Y. (Org.). A Geopolítica do inglês. São Paulo: Parábola, 2005. p. 135-159.

UFTM NEWS: TRADUÇÃO DE NOTÍCIAS. Facebook. 29 de junho, 2016. Disponível em: <www.facebook.com/UftmNews>. Acesso em: 17 out. 2016.

ZIPSER, M. E.; POLCHLOPEK, S. A. Do fato à reportagem: o ambiente da tradução jornalística. In: Dito Efeito, vol. 1, n 1. Curitiba, p. 1-15. Disponível em: <www.periodicos.utfpr.edu.br/de/article/view/2164>. Acesso em: 12 out. 2016.

\section{Como referenciar este artigo}

SOUSA Fernanda de.; CÓRDULA, Maíra Sueco Maegava. UFTM News: internacionalização e aprendizagem. Rev. EntreLínguas, Araraquara, v.3, n.1, p. 105124, jan./jun. 2017. Disponível em: <https://doi.org/10.29051/rel.v3.n1.janjun.2017.9355>. E-ISSN: 2447-3529.

Submetido em: 02/02/2017

Aprovado em: 23/03/2017 